\title{
The Low-Frequency Variability of the Southern Ocean Circulation
}

\author{
EMANUEL GIAROLLA \\ CPTEC/INPE, São José dos Campos, Brazil \\ RICARDO P. MATANO \\ College of Earth, Ocean, and Atmospheric Sciences, Oregon State University, Corvallis, Oregon
}

(Manuscript received 17 May 2012, in final form 1 February 2013)

\begin{abstract}
Long time series of sea surface height ( $\mathrm{SSH}$ ), sea surface temperature, and wind stress curl are used to determine the main modes of low-frequency variability of the Southern Ocean (SO) circulation. The dominant mode is a trend of increasing SSH at an average rate of $3.3 \mathrm{~mm} \mathrm{yr}^{-1}$. Similar trends have been reported in previous studies and the analysis indicates that the tendency of sea level increase over the SO has become more spatially homogeneous during the last decade, with changes in the increasing rate in 2000 and 2006. The other modes consist of stationary, basin-type modes, and an eastward-propagating wave. The stationary modes are particularly dominant in the Indian and Atlantic Ocean basins, where their spatial structure appears to be shaped by the basin geometry and the bottom topography. The wavelike patterns travel eastward with a period of approximately 10 years. Two waves were identified in the analysis: a complete cycle between 1997 and 2007 and a second cycle starting in 2000. Such waves have rarely been mentioned or identified in studies using recent satellite-derived SSH products.
\end{abstract}

\section{Introduction}

Relatively little is known about the interannual variability of the Southern Ocean (SO) circulation. Even its most widely investigated mode of low-frequency variability-the Antarctic Circumpolar Wave (ACW; first described by White and Peterson 1996 and Jacobs and Mitchell 1996) - is surrounded by controversy about its generation, coherence, and even its very existence (e.g., Park et al. 2004, and references therein). These uncertainties are rooted in the fact that, because of lack of alternative data sources, most studies of the SO variability have been focused on the analysis of remotely collected sea surface temperature (SST) observations, which are not ideally suited to characterize ocean circulation variability because they only represent the uppermost layer of the ocean. However, during the last two decades, remote altimeter sensors have collected reliable global information about sea surface height (SSH) anomalies that is more appropriate to characterize

Corresponding author address: Emanuel Giarolla, CPTEC/ INPE, Avenida dos Astronautas, 1758, São José dos Campos, SP, 12227-010, Brazil.

E-mail: emanuel.giarolla@cptec.inpe.br ocean circulation. Previous studies based on satellitederived SSH products with time length less than $15 \mathrm{yr}$, such as Qiu and Chen (2006), were unable to identify an ACW in their variability analysis, possibly because full cycles of the wave were not completed. Jacobs and Mitchell (1996) used a preliminary satellite-derived SSH field from 1986 to 1996 (with some gaps of data) to help their investigation of an ACW. They showed a good agreement between the patterns of observed SSH and those produced by a simplified model. In this study, the SSH data from 1993 to 2010, together with SST and wind stress curl fields, are used to identify the dominant modes of the low-frequency variability in the SO.

\section{Data and methods}

The SSH data were obtained from Archiving, Validation and Interpretation of Satellite Oceanographic data (AVISO) and Maps of Absolute Dynamic Topography (MADT; website http://www.aviso.oceanobs.com), which encompasses the period from 1993 to 2010 on a weekly basis. The SST data, from Reynolds et al. (2002), and the wind stress data, from the National Centers for Environmental Prediction (NCEP)-National Center for Atmospheric Research (NCAR) reanalysis project 

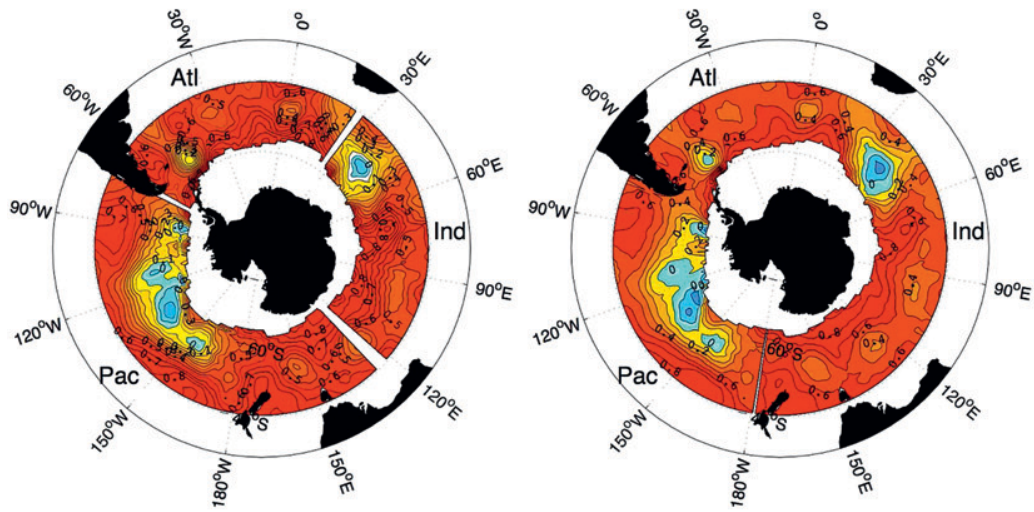

(a)
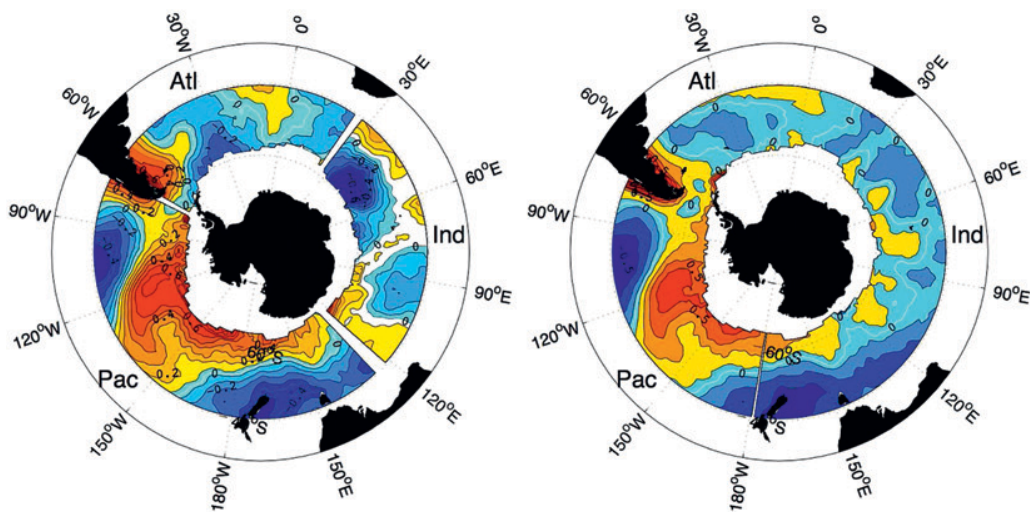

(b)
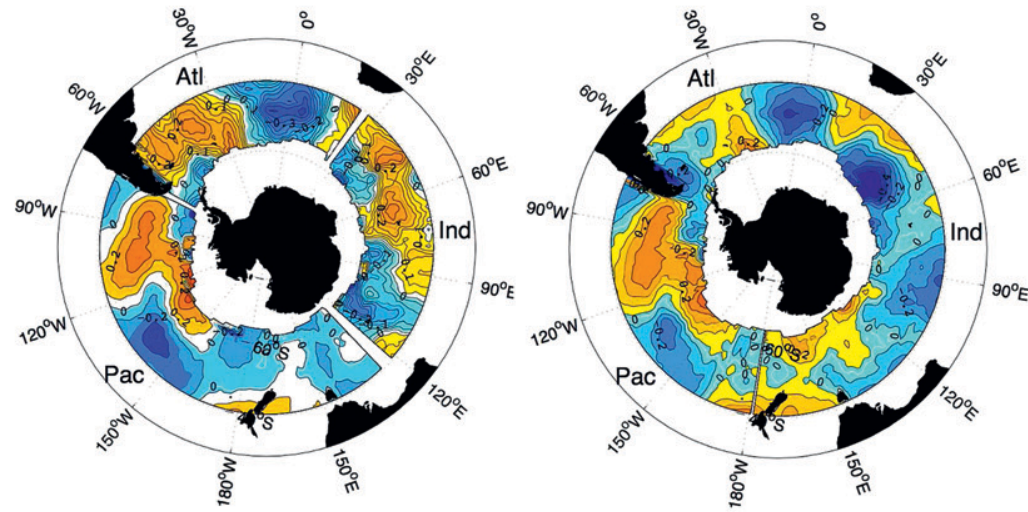

(c)
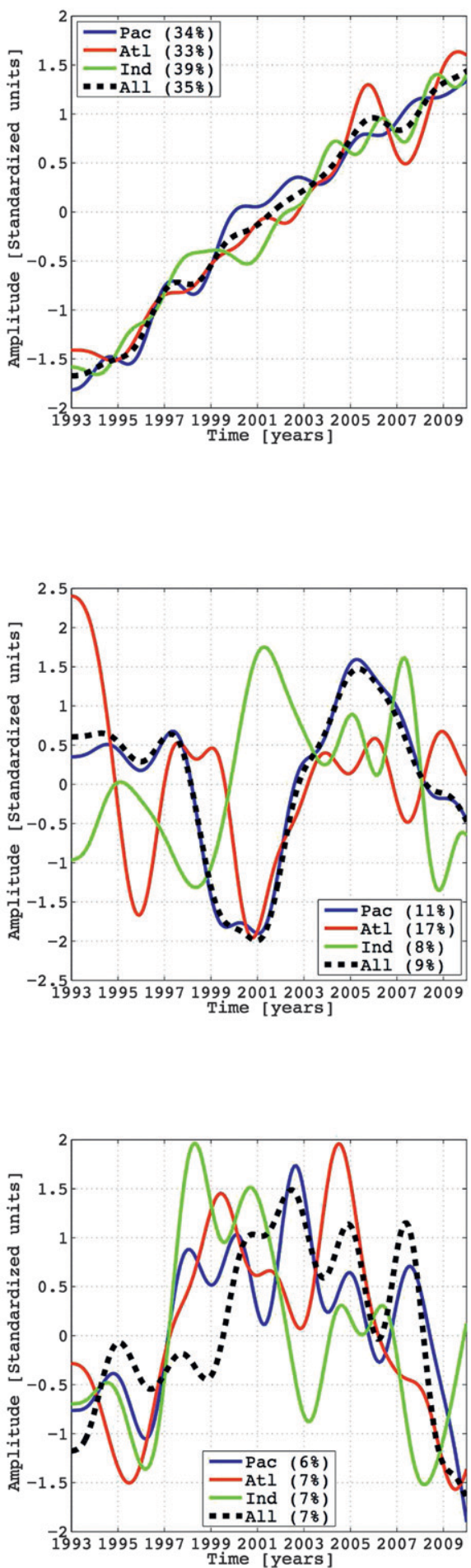

FIG. 1. (a) First, (b) second, and (c) third EOF modes of the SSH normalized anomalies from 1993 to 2010 for two cases: (left; spatial patterns) when each individual subbasin—South Atlantic, South Pacific, and South Indian Ocean—is considered separately, and (center; spatial patterns) when all circumpolar oceans together are considered; (right; plots) the respective coefficients time series with the blue, red, and green colors referring to Pacific, Atlantic, and Indian Oceans, respectively. Legends indicate the percentage of variance explained by each EOF mode and subbasin. The time series of the EOF analysis for the entire circumpolar domain is in dotted black. Contour range is $[-0.6,0.6]$ at 0.1 interval. 
(Kalnay et al. 1996), were downloaded from the International Research Institute for Climate and Society (IRI)-Lamont-Doherty Earth Observatory (LDEO) Climate Data Library (http://iridl.ldeo.columbia.edu/). To characterize the dominant modes of low-frequency variability, we calculated the empirical orthogonal functions (EOFs) of the SSH annual mean anomalies to discard the seasonal cycles and the $1 / 4^{\circ}$ weekly gridded data were averaged onto a $1^{\circ}$ grid to reduce the influence of small-scale perturbations. The domain was restricted to latitudes between $70^{\circ}$ and $40^{\circ} \mathrm{S}$ to minimize the influence of the tropical variability, which is not the scope of this work. Two approaches were used to calculate these EOFs. The first was to calculate the EOFs of the entire domain, and the second was to calculate EOFs for each individual subbasin. There are advantages and disadvantages for each approach. The first approach clearly identifies the dominant mode of variability but obscures regional variations particularly when-as in this casethere is a dominant mode of interbasin variability. Herein, we show the spatial patterns of the entire domain and regional EOFs together with the time series of both calculations. Differences between regional and circumpolar calculations are discussed within the text.

\section{Results}

The first EOF mode of SSH variability, which accounts for approximately $35 \%$ of the total variance for all basins, shows a trend of sea level rise (Fig. 1a). This overall increasing sea level trend, also captured in the EOF analysis of separated basins (Fig. 1a, left), has been well documented in previous studies (e.g., Cabanes et al. 2001; Cazenave and Nerem 2004; Willis et al. 2004; Lombard et al. 2005; Ishii et al. 2006; Qiu and Chen 2006). The leading causes are the steric expansion, due to changes in the heat and salt content of the water column, and the ocean mass redistribution produced by changes in the ocean circulation (Morrow et al. 2008; Lombard et al. 2005; Vivier et al. 2005; Roemmich et al. 2007; among others). A third contribution to the sea level rise could be an increase of the overall mass of the oceans (Cazenave et al. 2009). The relative contribution of these effects is uncertain. Previous studies estimated that steric expansion could explain approximately $50 \%-$ $60 \%$ of the total sea level rise (e.g., Guinehut et al. 2004; Lombard et al. 2005). Part of the sea level increase in the SO is presumably associated with changes of the oceanic circulation driven by variations of the atmospheric forcing. Roemmich et al. (2007), for example, posited that the positive SSH trend over the Pacific is a response of the oceanic circulation to a strengthening of the wind stress linked to the southern annular mode (SAM). (a)

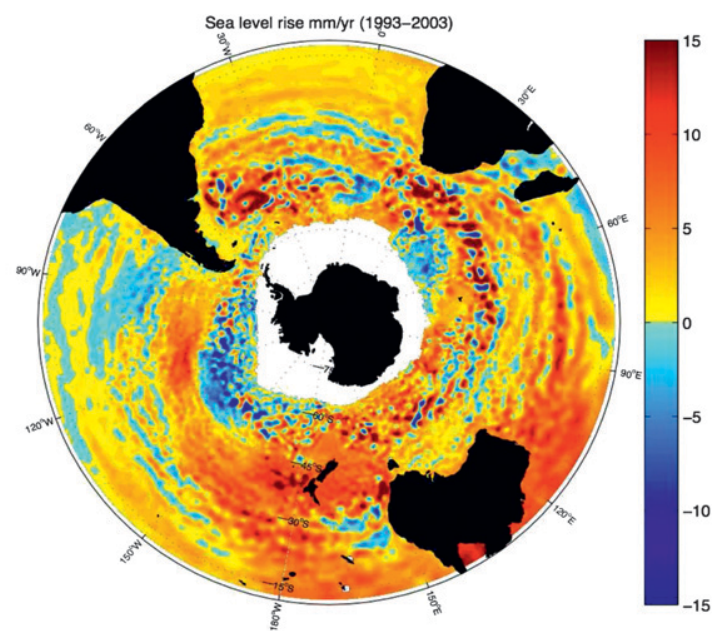

(b)

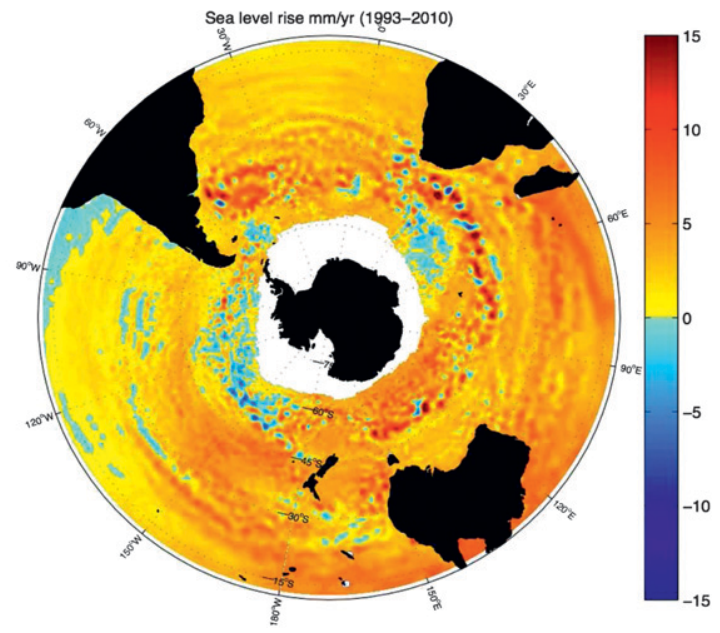

FIG. 2. Trends observed in altimetric SSH $\left(\mathrm{mm} \mathrm{yr}^{-1}\right)$ for the periods (a) 1993-2003 and (b) 1993-2010. The values were estimated through linear regression of monthly anomalies at each $1 / 4^{\circ}$ longitude $\times 1 / 4^{\circ}$ latitude grid point.

The increasing sea level trend, shown in the first EOF spatial pattern, is in qualitative agreement with the earlier results reported by, for example, Morrow et al. (2008) and Lombard et al. (2005), although our calculation shows a more widespread sea level increase. The differences can be attributed to the fact that Morrow et al. (2008) and Lombard et al. (2005) circumscribed their analysis to the period 1993-2003 (while we extended the analysis until 2010) and to the different methodology used to compute the trends. To make a more quantitative comparison between both estimates, we represented in Fig. 2a a computation of the SSH linear trend for their original 1993-2003 period, and in Fig. 2b the time period was extended until 2010. The comparison indicates that during the last 7 years there has been an expansion of the 
(a)

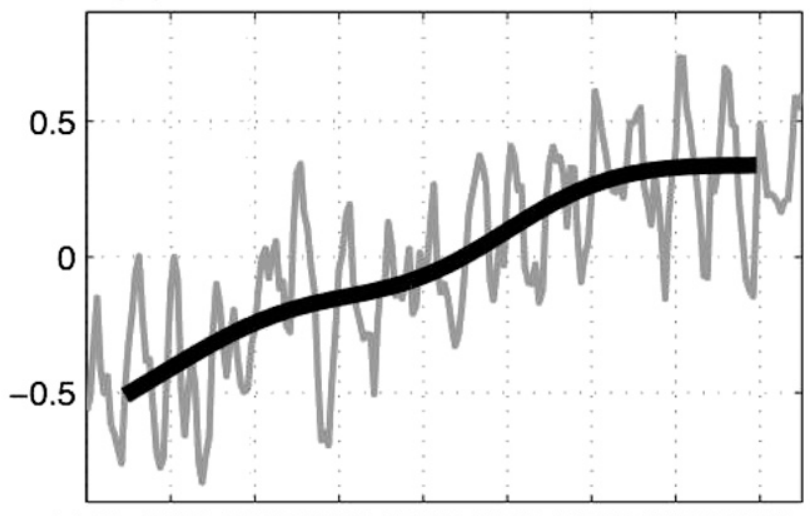

199319951997199920012003200520072009

(b)

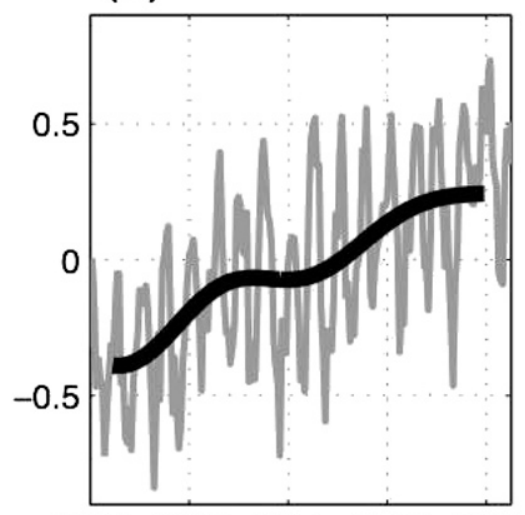

19931997200120052009 (c)

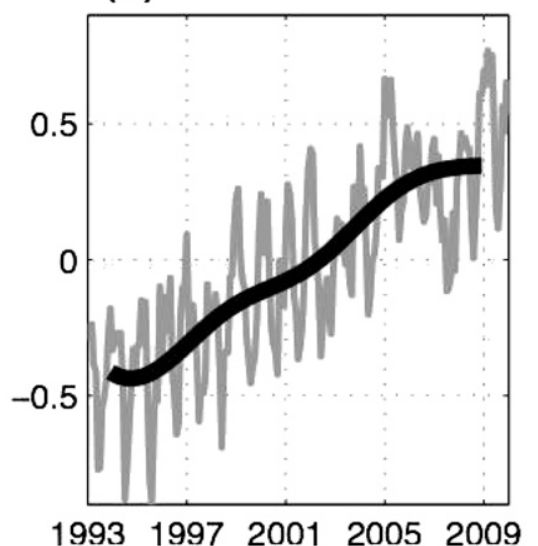

(d)

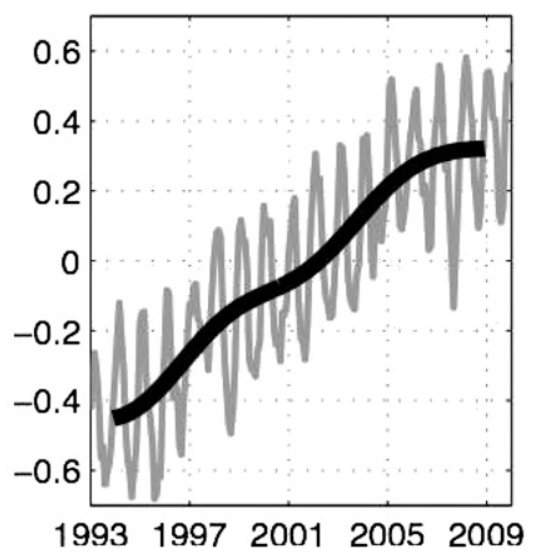

FIG. 3. The monthly SSH normalized anomalies with seasonal cycles and averaged between $70^{\circ}$ and $40^{\circ} \mathrm{S}$ for (a) Pacific $\left(150^{\circ} \mathrm{E}-70^{\circ} \mathrm{W}\right)$, (b) Indian $\left(27^{\circ}-122^{\circ} \mathrm{E}\right)$, (c) Atlantic $\left(70^{\circ} \mathrm{W}-25^{\circ} \mathrm{E}\right)$, and (d) all oceans. The black thick curves represent the respective low-pass $(3$-yr) filtered values.

regions with increasing tendencies. In fact, with the exception of relatively small patches to the southeast of Africa and in the southern Pacific, most of the SO now shows an overall sea level increase. The averaged linear increasing trend, for the Southern Hemisphere oceans at the latitudinal range considered in Figs. $2 \mathrm{a}$ and $2 \mathrm{~b}\left(70^{\circ}-\right.$ $13^{\circ} \mathrm{S}$ ), is about $3.3 \mathrm{~mm} \mathrm{yr}^{-1}$, significant at the $95 \%$ confidence level by the Mann-Kendall test. According to Cazenave et al. (2009), when not only the SO but global oceans are considered, altimetry-based data indicated a sea level rise rate of approximately $3.1 \mathrm{~mm} \mathrm{yr}^{-1}$ during 1993-2003 and $2.5 \mathrm{~mm} \mathrm{yr}^{-1}$ over 2003-08. Cazenave et al. (2009) also report that after 2003 the contribution of steric expansion has not been preponderant, and since then the sea level rise of the global oceans has been caused mainly by land ice contributions. The dominance of the trend of sea level rise observed in the time series of the first EOF was confirmed by an ancillary calculation using detrended data. In this case, all the EOFs move a rank upward without significant changes in their spatial or temporal structures. The overall SSH trend rate on the SO since 1993 has not been linear. Lee and McPhaden (2008) detected a change of the decadal tendencies in the SSH of the Indo-Pacific region at the end of the twentieth century. In Fig. 3a of our study, the time series of averaged SSH anomalies over the Pacific region $\left(70^{\circ}-40^{\circ} \mathrm{S}, 150^{\circ} \mathrm{E}-70^{\circ} \mathrm{W}\right)$ shows a trend with an inflection around the year 2000, in agreement with the Lee and McPhaden (2008) study, and a new inflection in 2006, indicating a new change of tendency in the South Pacific SSH anomalies in this last decade. Analogous time series calculated for the Indian $\left(27^{\circ}-122^{\circ} \mathrm{E}\right)$ and Atlantic $\left(70^{\circ} \mathrm{W}-25^{\circ} \mathrm{E}\right)$ Oceans, and for all oceans together (Figs. 3b-d), show comparable inflections of the 


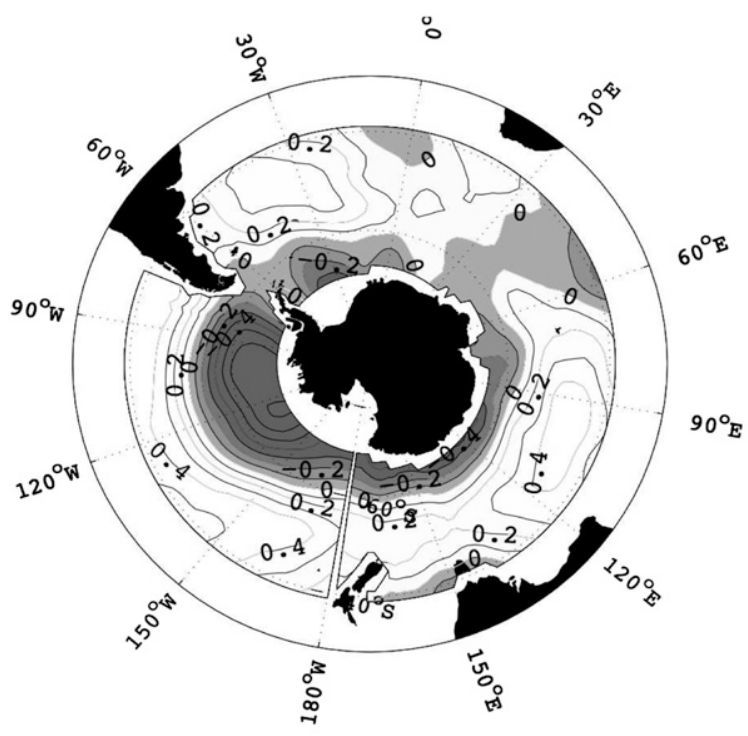

(a)

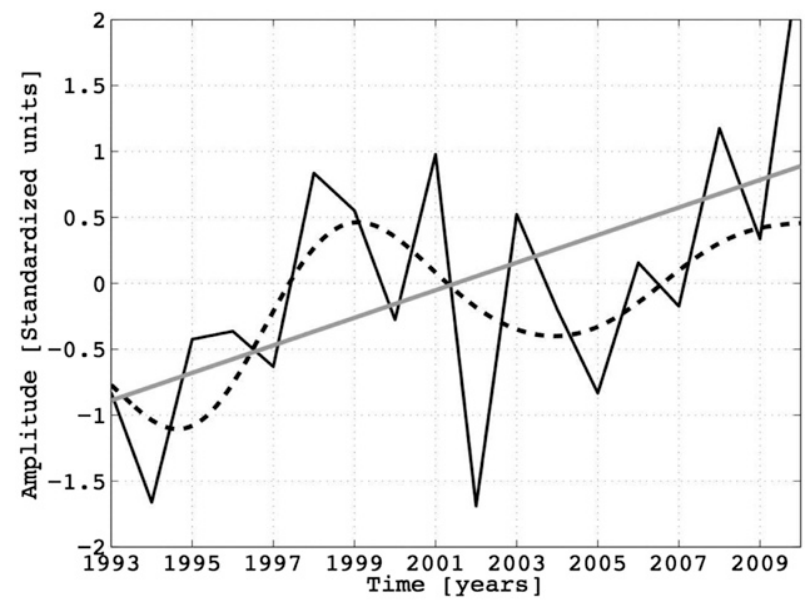

(b)

FIG. 4. First EOF mode for the annual wind stress curl normalized anomalies, computed between $70^{\circ}$ and $40^{\circ} \mathrm{S}$ for the SO: (a) the spatial pattern contours at 0.2 interval (negative values shaded) and (b) the coefficient time series (solid curve) together with its low-pass (3-yr) filtered values (dashed curve) and the estimated linear trend (gray solid line).

trend in 2000 and 2006. Lee and McPhaden (2008) suggest that these changes can be linked to variations in the strength of subtropical and subpolar gyres. To check whether similar changes are found in atmospheric fields, an analysis of the wind stress curl anomalies was made. The first EOF mode, between $70^{\circ}$ and $40^{\circ} \mathrm{S}$ and with the seasonal cycle removed prior to the calculation, is shown in Fig. 4. This first mode is known to represent the influence of the SAM on the SO winds (Iijima et al. 2009 and references therein). In fact, the correlation coefficient between the time series of the first mode shown in Fig. 4 and the SAM index (Nan and Li 2003) is 0.78, while the following EOF modes time series are not correlated at the $95 \%$ confidence level. The first EOF time series shows a linear trend (gray line in Fig. 4b), and the lowfrequency variability of this mode (dashed curve in Fig. 4b) shows inflections approximately in 1999 and 2004. These changes apparently represent the climate signal in the SAM mode that could be associated with the changes in the SSH trend, reinforcing the suggestions of Roemmich et al. (2007) and Lee and McPhaden (2008) that changes in the wind stress curl pattern influence the SSH via mass distribution changes.

The second and third EOF modes of SSH variability account for approximately $8 \%$ and $7 \%$ of the Indian Ocean, $17 \%$ and $7 \%$ of the Atlantic, and $11 \%$ and $6 \%$ of the Pacific total variance. These modes show structures characterized by alternating patterns of positive and negative SSH spatial amplitudes (Figs. 1b,c). The largest amplitudes are observed in the South Pacific basin and correspond with wind stress maxima in that region (Hughes et al. 2003; Vivier et al. 2005). The time series of the second EOF over the Pacific basin shows a wavelike pattern within a period of $10-11 \mathrm{yr}$ according to a periodogram analysis (not shown), changing sign between 1998, 2002, and 2008. The periodogram of the third EOF contains higher-frequency oscillations, with periods of approximately $5-8 \mathrm{yr}$. The observed similarities between the circumpolar and the regional EOFs in the South Pacific reflect the strong influence of the Pacific Ocean on the overall variability. Note, for example, that the time series of the second EOF of the circumpolar mode are nearly identical to those in the Pacific sector (Fig. 1b, right). The Pacific and Atlantic variabilities are also connected by in-phase variations of the wind stress forcing (Fig. 4a). The two regions are also dynamically linked by the Antarctic Circumpolar Current, which rapidly advects ocean perturbations from the southeastern Pacific into the southwestern Atlantic (Fetter and Matano 2008).

The second and third EOF patterns show that bottom topography plays an important role in the SO variability. The South Atlantic's EOFs, for example, show a dipole structure with perturbations of opposite signs on either side of the Mid-Atlantic Ridge, resembling standing modes bounded by the bottom topography. Similar signatures of topography are also evident in the Pacific and Indian Ocean basins where the East Pacific Rise and the Southwest and Southeast Indian Ocean Ridges mark the change of sign of the amplitudes of the second and third EOFs of these regions (Fig. 1c). Previous studies, which focused on the high-frequency (barotropic) portion of the variability spectrum, had already shown the influence of the bottom topography on the SO variability 

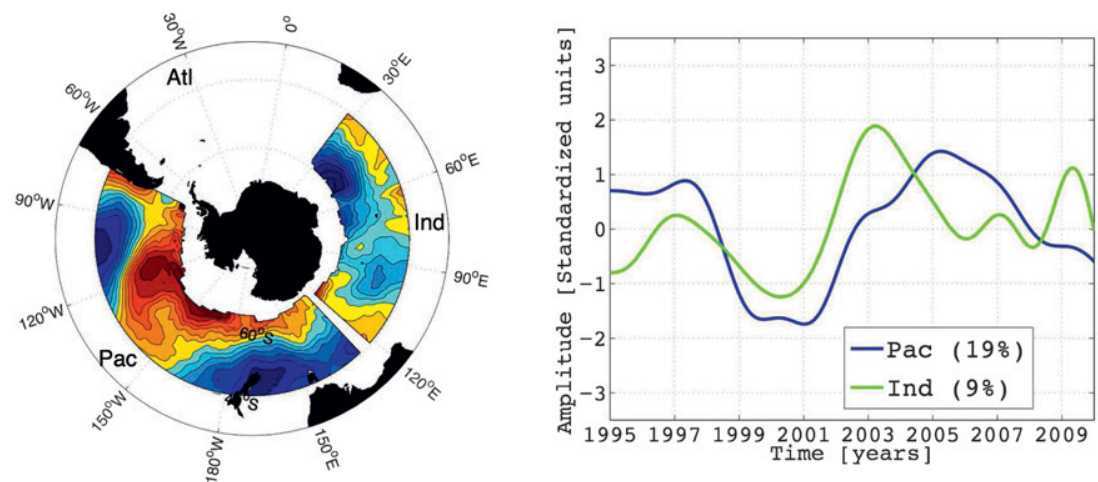

(a)
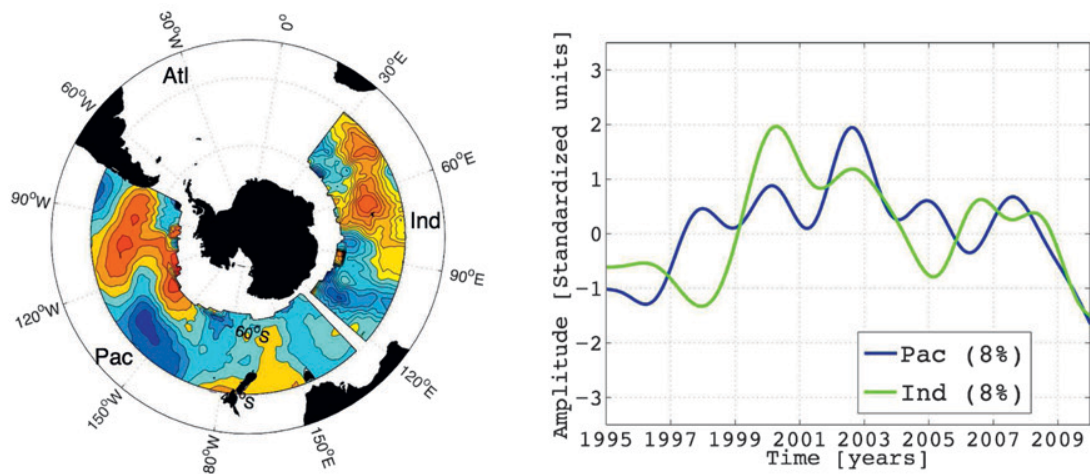

(b)
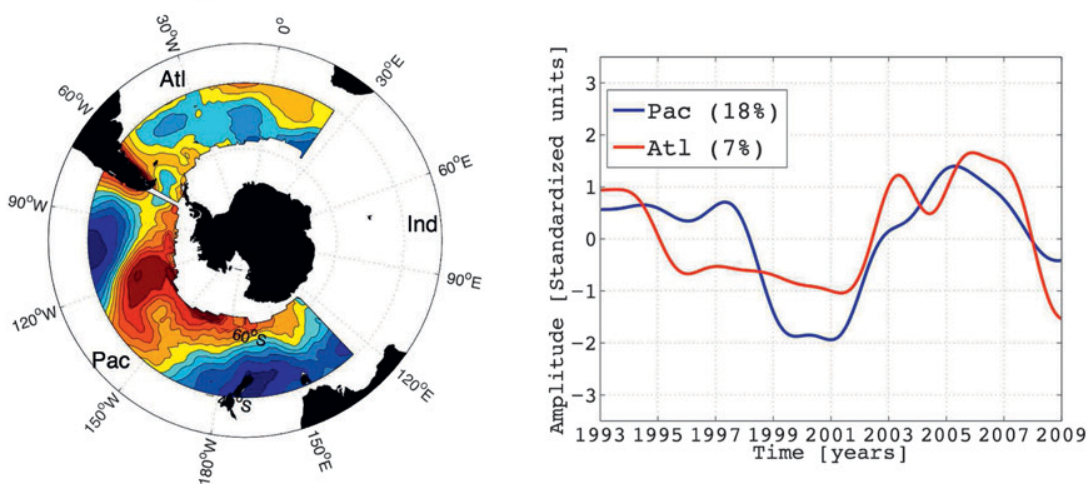

(c)
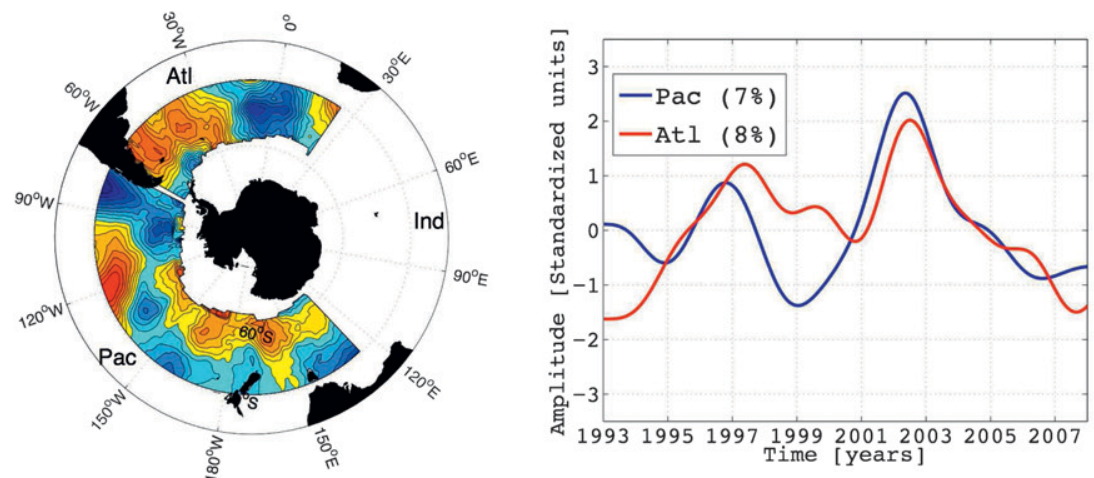

(d)

FIG. 5. Spatial patterns and respective time series of the EOFs computed with SSH normalized anomalies for the (a) second Pacific EOF and second Indian Ocean EOF computed with a lag $=+2$ (see text); (b) third Pacific EOF and third Indian Ocean EOF, lag $=+2$; (c) second Pacific EOF and third Atlantic EOF, lag = -1 ; and (d) third Pacific EOF and second Atlantic EOF, lag $=-2$. In the time series, blue, green, and red lines represent Pacific, Indian, and Atlantic Oceans, respectively. The legends also indicate the percentage of variance explained by each EOF mode and subbasin. Contour range is $[-0.6,0.6]$ at 0.1 interval. 

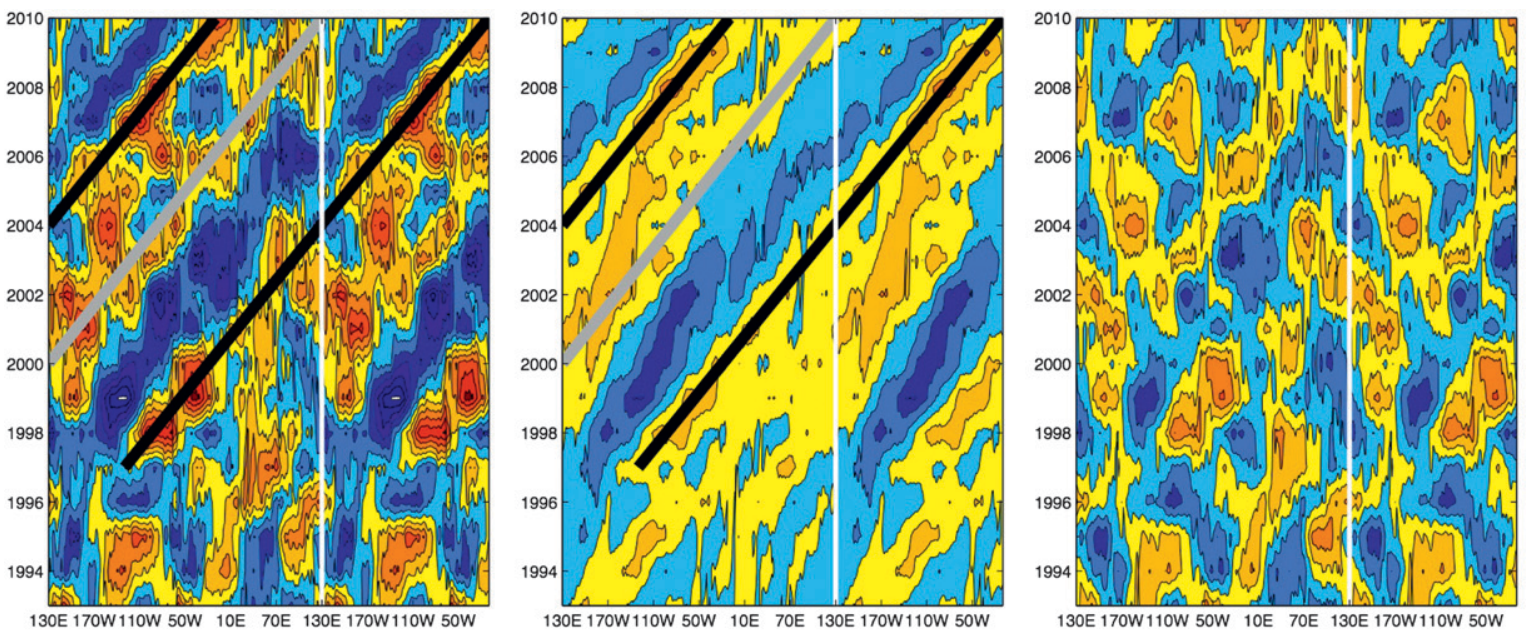

(a)
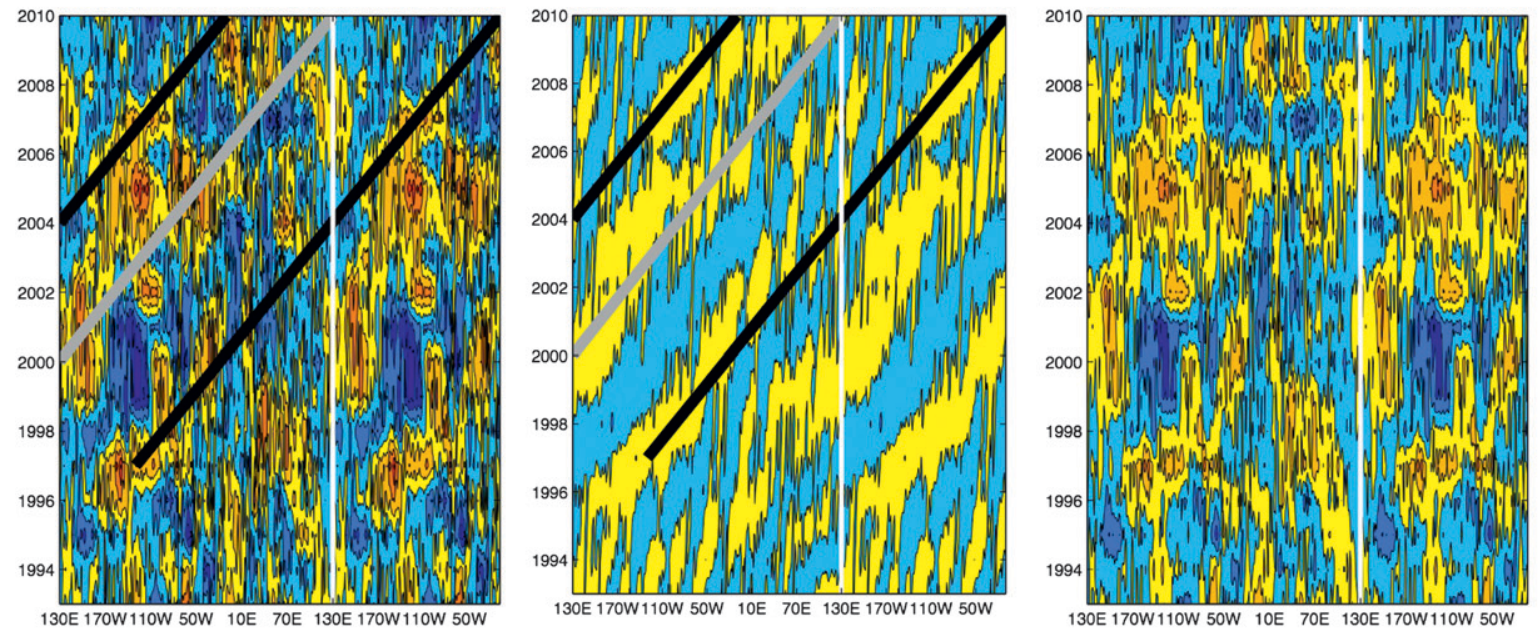

(b)
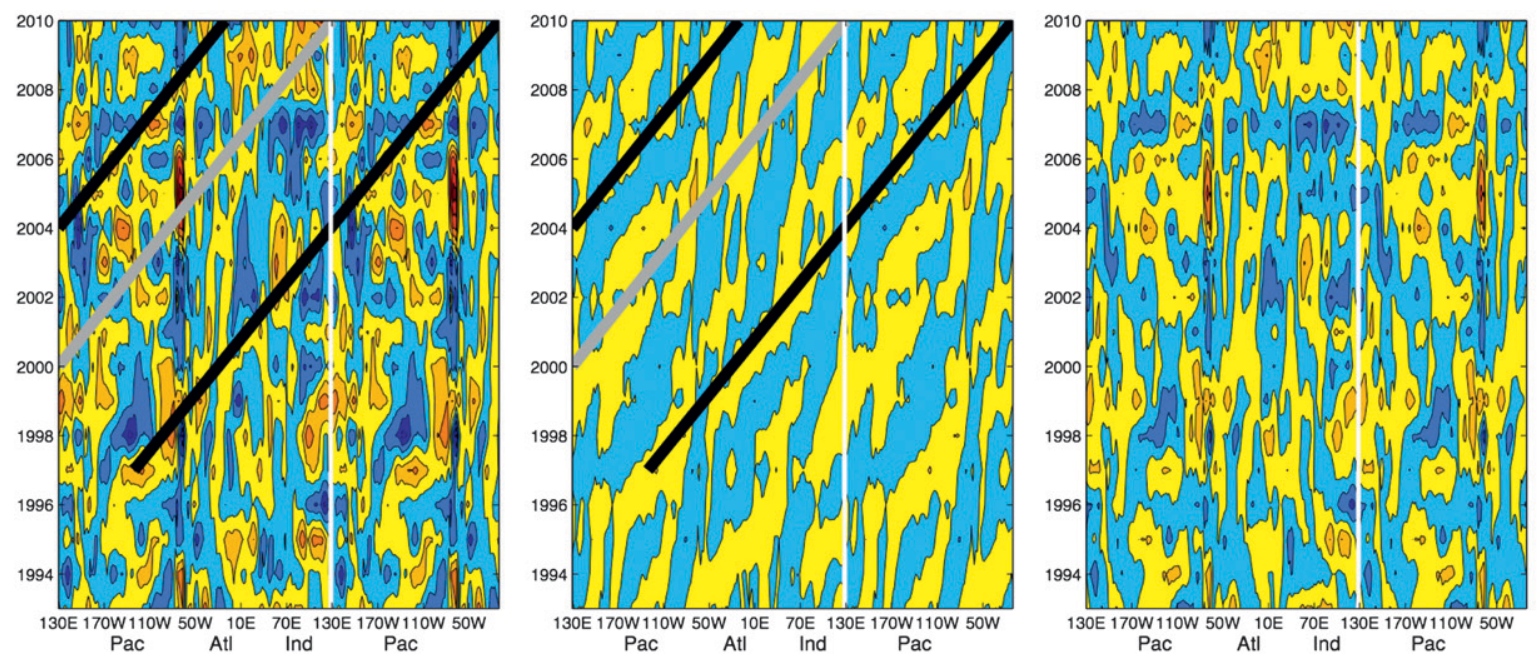

(c)

FIG. 6. Time-longitude (Hovmöller) diagrams for (a) SST, (b) SSH, and (c) wind stress curl annual normalized anomalies, without linear trend and averaged between $40^{\circ}$ and $70^{\circ} \mathrm{S}$. The first column represents the total anomalies, and the second and third are the eastward and stationary components, respectively. The black and gray lines correspond to waves propagating (see text). The value range for all diagrams is $[-1.5,1.5]$ at 0.3 contour intervals. The Pacific and Atlantic sectors are duplicated for a better visualization. 
(Hughes et al. 2003; Weijer and Gille 2005). Our analysis indicates that similar modes are also evident in the lowfrequency portion of the spectrum. We surmise that the observed variations represent low-frequency modulations of topographically trapped modes. Such modulation has already been documented in the Argentinean basin (Saraceno et al. 2004).

The variability patterns described above are characterized by a circumpolar structure of highs and lows with regional variations. The wavelike structure of this pattern is emphasized by the near quadrature of the time series of the second and third EOFs of the circumpolar calculation, which is symptomatic of propagating phenomena (Figs. 1b,c). The regional EOFs were also computed with 1 or 2 years removed prior to calculations, at the beginning or the end of the data, to be intercompared with lags in time. The lagged correlation of the time series of the regional modes is further evidence of a propagating phenomenon. For example, the correlation between the second mode of the Indian Ocean sector and the second mode of the Pacific sector increases from 0.0 to 0.48 with a time lag of +2 for the Indian Ocean sector (i.e., events from the Indian Ocean precede by 2 years those in the Pacific Ocean; Fig. 5a). The correlation between the third mode of the Indian Ocean and the third mode of the Pacific increases from 0.21 to 0.61 (also with a time lag of +2 ; Fig. $5 b$ ). The time series of the Pacific and Atlantic are similarly correlated. The second mode of the Pacific and the third mode of the Atlantic have a correlation of 0.68 with a time lag of -1 , while the third mode of the Pacific has a correlation of 0.62 with the second mode of the Atlantic with a time lag of -2 (Figs. $5 \mathrm{c}, \mathrm{d})$. Thus, the significant correlations between modes at 1-2-yr time lags indicate that these modes might represent the same phenomenon, differing only by a phase shift.

To further investigate the propagating nature of the patterns described above, we constructed Hovmöller diagrams of detrended SSH, SST, and wind stress curl annual anomalies for the latitudinal band between $40^{\circ}$ and $70^{\circ} \mathrm{S}$ (Fig. 6, first column). At least two circumpolar waves can be identified in those diagrams, although it is not straightforward to separate them because (as seen in Fig. 6) anomalies of a propagating wave can possibly merge with those of another new wave being generated. Despite this, we defined one wave starting in the east Pacific region, and propagating from 1997 to 2010 and probably beyond (black thick lines, Fig. 6) and a second wave from 2001 to 2010 (gray lines, Fig. 6). The first wave completes a cycle around the globe in approximately 10 years. For the first wave, the anomalies are most intense in the Pacific and Atlantic sectors $\left(110^{\circ} \mathrm{W}-\right.$ $\left.10^{\circ} \mathrm{E}\right)$. The propagating patterns are similar to those ascribed to the ACW. The signal is more clearly defined

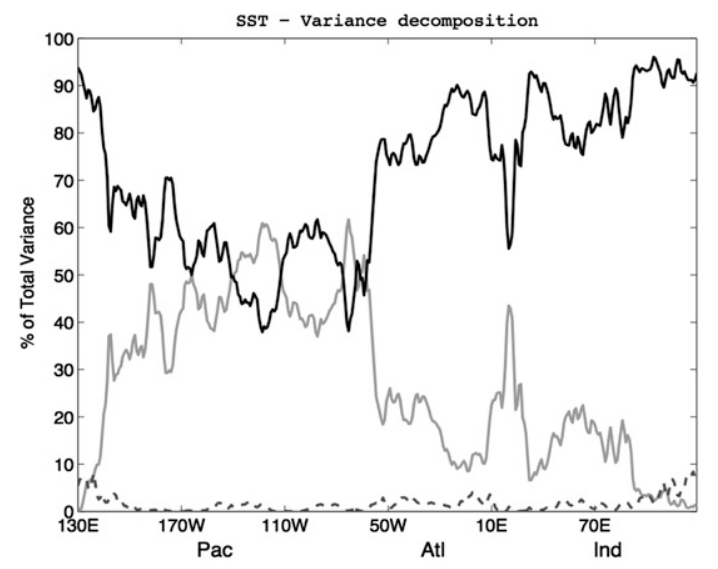

(a)

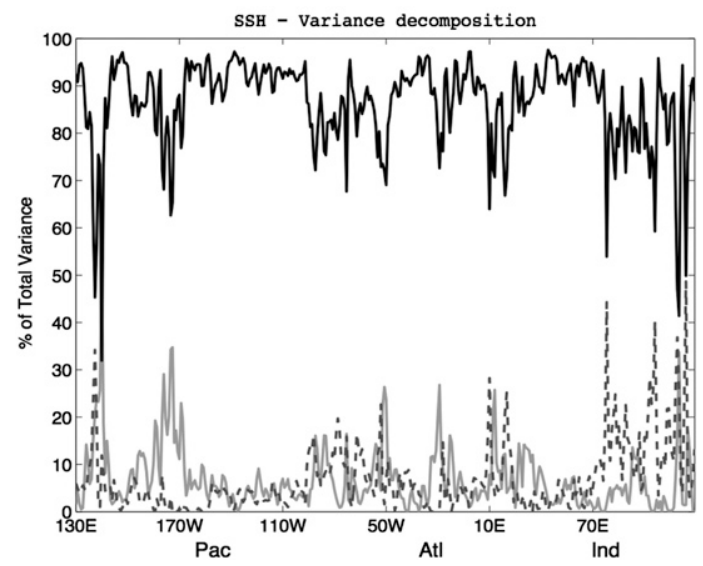

(b)

FIG. 7. The total variance decomposition into stationary component variance (black) and eastward- (light gray) and westwardpropagating (dashed) component variances for (a) SST and (b) SSH annual anomalies.

in the SST than in the SSH and the wind stress curl data. To quantify the contribution of the eastward-propagating signal to the variability of each of these variables we separated the eastward-propagating component from the stationary component using the method described by Park et al. (2004), where longitude-time variations of SST, SSH, and wind stress curl are represented as a sum of Fourier harmonics composed of westward- and eastward-propagating waves and standing waves are defined as the sum of two waves of equal amplitude propagating in opposite directions. These components are shown in Fig. 6, second and third columns. The results show a clear eastward-propagating signal in the SST, SSH, and wind stress curl fields, especially in the Pacific Ocean. For a more quantitative evaluation of the propagating and stationary contribution, Fig. 7 shows the variance decomposition for the three componentsstationary, eastward, and westward-in relation to the total variance. The eastward-propagating component in the SST signal accounts for approximately $50 \%$ of the total variance in the Pacific (Fig. 7a), while in the other 

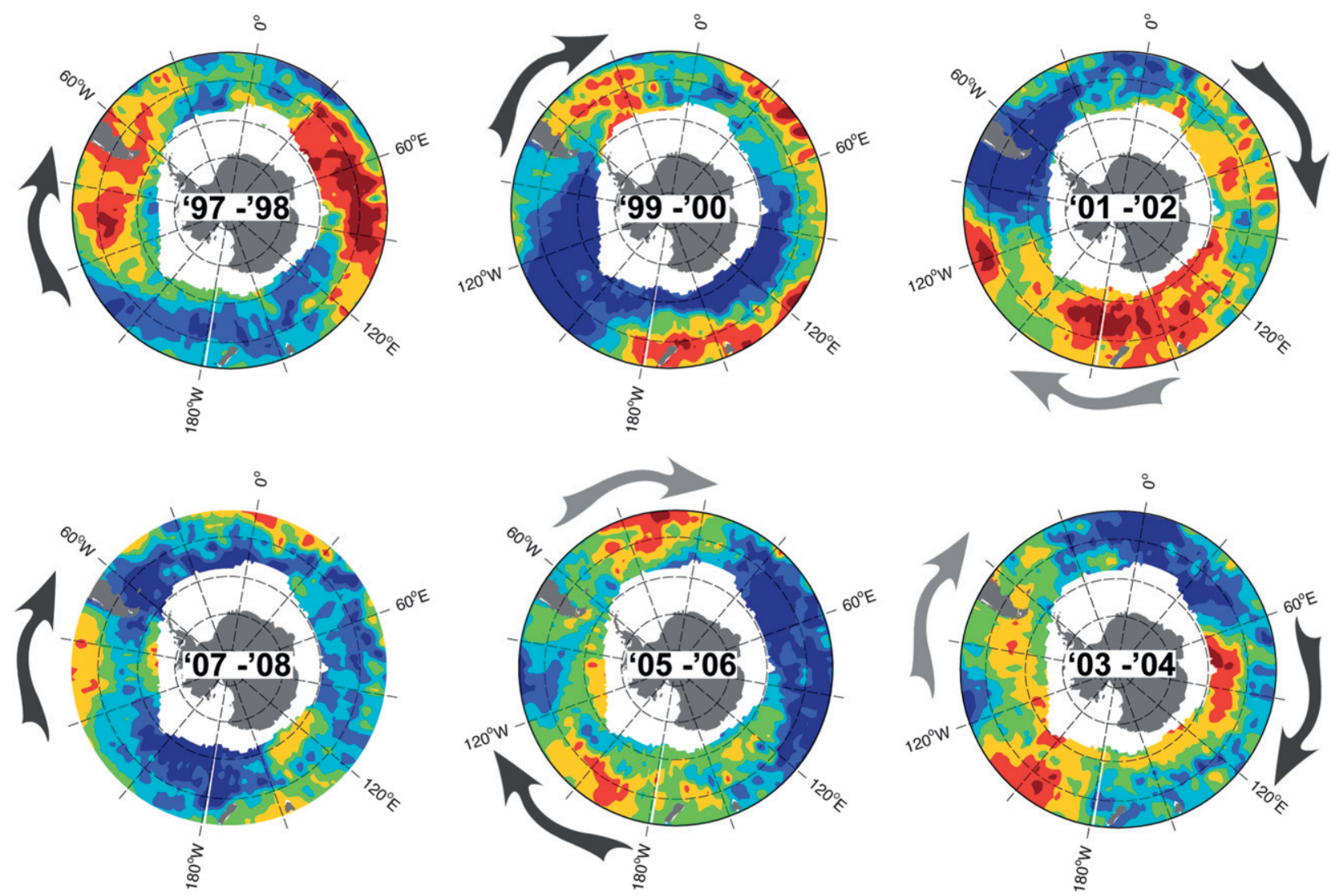

FIG. 8. Maps of SST anomalies $\left({ }^{\circ} \mathrm{C}\right), 2-y r$ averaged from the biennium $1997-98$ to 2007-08. The arrows indicate the propagation of positive anomalies (see text).

basins the stationary component accounts for a higher amount of the total variance. The eastward-propagating component of the total variance of the SSH signal (Fig. 7b), and of the wind stress curl signal (not shown), are substantially smaller than their stationary components for all the basins. The westward component of the SST variance is negligible (e.g., Park et al. 2004), but the westward component of the $\mathrm{SSH}$, which represents Rossby waves (e.g., Qiu and Chen 2006), is not negligible. The larger contribution of the eastward-propagating component to the SST variability indicates that this signal is largely confined to the upper layers of the ocean. The SSH anomalies, which are more influenced than the SST anomalies by variability in the deeper layers, do not show such a dominant contribution. In addition, the relation between SSH and SST is particularly difficult to establish in the ACW because it involves a coupled oceanatmosphere phenomenon (see, e.g., Venegas 2003 and references therein). SSTs are essentially advected by the geostrophic currents generated by the $\mathrm{SSH}$ gradients, but SSTs are not a passive tracer since they influence the overlying atmosphere and, hence, the wind stress distribution that forces the SSHs.
To further illustrate the eastward-propagating phenomenon we mapped SST anomalies during the 19972008 period (Fig. 8). The black arrows in those maps indicate the displacement of the positive anomalies associated with the first wave (Fig. 6), which in 1997-98 are in the east Pacific-Atlantic region, and the gray arrows represent the traveling positive anomalies of the second wave, which initiated over the Pacific Ocean between $120^{\circ}$ and $180^{\circ} \mathrm{E}$. The ACW is basically seen as a wave- 2 pattern, with positive and negative anomalies alternating around the pole. Bian and Lin (2012) posited that some studies, especially those using coupled models, have found that wavenumber 3 is the dominant pattern around Antarctica. However, for the period 1981-2010, their results with reanalysis data indicate that the ACW has a strong tendency toward the wave- 2 pattern. The maps of Fig. 8 reveal a complete cycle between 1997 and 2007 approximately and a second that started in 2001, in accordance with the time-longitude diagram presented in Fig. 6. The positive anomalies associated with the second wave were apparently dispersing in the Indian Ocean sector after 2007. These propagating patterns had not been identified in the SSH analysis of previous 
studies. Qiu and Chen (2006) identified two dominant modes of SSH variability in the South Pacific, using data from October 1992 to February 2005. The first was a sea level trend while the second mode was associated with the occurrence of the 1997-98 El Niño. As shown in our work, with the SSH data updated to 2010 an additional mode of variability appears, representing the ACW.

\section{Discussion and conclusions}

Three modes of variability characterize the SO circulation. The dominant mode is a trend of increasing sea level that has become more spatially uniform during the last 7 years and shows changes of slope in 2000 and 2006 (Fig. 3). The other modes consist of stationary and basintype modes and an eastward-propagating wave. The overall variability is a superposition of propagating and stationary modes, but the particular contribution of standing and propagating signals vary from basin to basin. The stationary modes are particularly dominant in the Indian and Atlantic Ocean basins, where their spatial structure is shaped by the basin geometry and the bottom topography. Our analysis also indicates that SSTs and SSHs have different contributions from steady and propagating signals. We hypothesize that is because the propagating signal is an upper-ocean phenomenon, which is more obvious in the SSTs than in the SSHs. There has been considerable discussion about whether the eastward-propagating wave is a forced response to ENSO events in the Pacific Ocean or a self-sustained oscillation (Venegas 2003). Park et al. (2004) argued that most of the SO variability can be explained by a standing wave pattern associated with ENSO episodes. They concluded that eastward propagation represents a relatively minor portion of the SST variability and that the propagating signal has an intermittent phase and a variable propagation speed. Our analysis, however, suggests that eastward propagation is a robust feature of the SO variability-it is observed in the SST, mainly in the Pacific Ocean, and in the SSH and wind stress curl fields-it accounts for a significant portion of the ocean variability and it has a coherent speed and phase. Ancillary analysis (not included herein) shows an out of phase relation between the SST and wind stress curl anomalies that is consistent with the self-sustaining mechanism postulated by Qiu and Chen (2006). It is not possible to ascertain whether the propagating anomalies could develop independently of ENSO forcing, but observations indicate that these anomalies appear to be a natural mode of oscillation of the SO. It is apparent, however, that the persistence of this signal is hampered by the presence of the South American continent. Note, for example, that the percentage of the variability accounted for this wave drops toward the Atlantic and the Indian Ocean basins. It is also apparent that the persistence of the wave patterns is affected by the intermittent generation of new waves; for instance, while the first wave described in Fig. 6 was still propagating, an additional wave, which had been generated by a new ENSO event that happened at the same period, followed the previous one.

Acknowledgments. The authors thank the editor and reviewers for their helpful comments and suggestions. E. Giarolla acknowledges the support of the Conselho Nacional de Desenvolvimento Científico e Tecnológico (CNPQ) through Grant 200559/2008-7 and of the Brazilian National Institute for Space Research (INPE). R. P. Matano acknowledges the financial support of the National Science Foundation through Grant OCE0928348 and of NASA through Grants NNX08AR40G and NNX12AF67G.

\section{REFERENCES}

Bian, L. G., and X. Lin, 2012: Interdecadal change in the Antarctic Circumpolar Wave during 1951-2010. Adv. Atmos. Sci., 29, 464-470, doi:10.1007/s00376-011-1143-z.

Cabanes, C., A. Cazenave, and C. Le Provost, 2001: Sea level rise during past 40 years determined from satellite and in situ observations. Science, 294, 840-842.

Cazenave, A., and R. S. Nerem, 2004: Present-day sea level change: Observations and causes. Rev. Geophys., 42, RG3001, doi:10.1029/2003RG000139.

_ , K. Dominh, S. Guinehut, E. Berthier, W. Llovel, G. Ramillien, M. Ablain, and G. Larnicol, 2009: Sea level budget over 2003-2008: A reevaluation from GRACE space gravimetry, satellite altimetry and Argo. Global Planet. Change, 65, 83-88, doi:10.1016/j.gloplacha.2008.10.004.

Fetter, A. F. H., and R. P. Matano, 2008: On the origins of the variability of the Malvinas Current in a global, eddy-permitting numerical simulation. J. Geophys. Res., 113, C11018, doi:10.1029/ 2008JC004875.

Guinehut, S., P. Y. Le Traon, G. Larnicol, and S. Philipps, 2004: Combining Argo and remote-sensing data to estimate the ocean three-dimensional temperature fields-A first approach based on simulated observations. J. Mar. Syst., 46, 85-98.

Hughes, C. W., P. L. Woodworth, M. P. Meredith, V. Stepanov, T. Whitworth, and A. R. Pyne, 2003: Coherence of Antarctic sea levels, Southern Hemisphere annular mode, and flow through Drake Passage. Geophys. Res. Lett., 30, 1464, doi:10.1029/ 2003GL017240.

Iijima, Y., S. Aoki, and K. Kutsuwada, 2009: The Southern annular mode and opposite-phased basin mode of the Southern Ocean circulation. J. Oceanogr., 65, 53-60, doi:10.1007/ s10872-009-0005-0.

Ishii, M., M. Kimoto, K. Sakamoto, and S.-I. Iwasaki, 2006: Steric sea level changes estimated from historical ocean subsurface temperature and salinity analyses. J. Oceanogr., 62, 155-170.

Jacobs, G. A., and J. L. Mitchell, 1996: Ocean circulation variations associated with the Antarctic Circumpolar Wave. Geophys. Res. Lett., 23 (21), 2947-2950.

Kalnay, E., and Coauthors, 1996: The NCEP/NCAR 40-Year Reanalysis Project. Bull. Amer. Meteor. Soc., 77, 437-471. 
Lee, T., and M. J. McPhaden, 2008: Decadal phase change in largescale sea level and winds in the Indo-Pacific region at the end of the 20th century. Geophys. Res. Lett., 35, L01605, doi:10.1029/ 2007GL032419.

Lombard, A., A. Cazenave, P. Y. Le Traon, and M. Ishii, 2005: Contribution of thermal expansion to present-day sea level change revisited. Global Planet. Change, 47, 1-16.

Morrow, R., G. Valladeau, and J.-B. Sallee, 2008: Observed subsurface signature of Southern Ocean sea level rise. Prog. Oceanogr., 77, 351-366.

Nan, S., and J. Li, 2003: The relationship between summer precipitation in the Yangtze River valley and the boreal spring Southern Hemisphere annular mode. Geophys. Res. Lett., 30, 2266, doi:10.1029/2003GL018381.

Park, Y.-H., F. Roquet, and F. Vivier, 2004: Quasi-stationary ENSO wave signals versus the Antarctic Circumpolar Wave scenario. Geophys. Res. Lett., 31, L09315, doi:10.1029/2004GL019806.

Qiu, B., and S. Chen, 2006: Decadal variability in the large-scale sea surface height field of the South Pacific Ocean: Observations and causes. J. Phys. Oceanogr., 36, 1751-1762.

Reynolds, R. W., N. A. Rayner, T. M. Smith, D. C. Stokes, and W. Wang, 2002: An improved in situ and satellite SST analysis for climate. J. Climate, 15, 1609-1625.
Roemmich, D., J. Gilson, R. Davis, P. Sutton, S. Wijffels, and S. Riser, 2007: Decadal spinup of the South Pacific subtropical gyre. J. Phys. Oceanogr., 37, 162-173.

Saraceno, M., C. Provost, A. R. Piola, J. Bava, and A. Gagliardini, 2004: Brazil Malvinas frontal system as seen from 9 years of advanced very high resolution radiometer data. J. Geophys. Res., 109, C05027, doi:10.1029/2003JC002127.

Venegas, S. A., 2003: The Antarctic Circumpolar Wave: A combination of two signals? J. Climate, 16, 2509-2525.

Vivier, F., K. A. Kelly, and M. Harismendy, 2005: Causes of largescale sea level variations in the Southern Ocean: Analysis of sea level and a barotropic model. J. Geophys. Res., 110, C09014, doi:10.1029/2004JC002773.

Weijer, W., and S. T. Gille, 2005: Adjustment of the Southern Ocean to wind forcing on synoptic time scales. J. Phys. Oceanogr., 35, 2076-2089.

White, W. B., and R. G. Peterson, 1996: An Antarctic Circumpolar Wave in surface pressure, wind, temperature and sea-ice extent. Nature, 380, 699-702.

Willis, J. K., D. Roemmich, and B. Cornuelle, 2004: Interannual variability in upper ocean heat content, temperature, and thermosteric expansion on global scales. J. Geophys. Res., 109, C12036, doi:10.1029/2003JC002260. 